\title{
Anterior shear strength of the porcine lumbar spine after laminectomy and partial facetectomy
}

\author{
Guido B. van Solinge $\cdot$ Albert J. van der Veen • \\ Jaap H. van Dieën · Idsart Kingma • \\ Barend J. van Royen
}

Received: 11 January 2010/Revised: 2 May 2010/ Accepted: 11 June 2010/Published online: 27 June 2010

(C) The Author(s) 2010. This article is published with open access at Springerlink.com

\begin{abstract}
Degenerative lumbar spinal stenosis is the most common reason for lumbar surgery in patients in the age of 65 years and older. The standard surgical management is decompression of the spinal canal by laminectomy and partial facetectomy. The effect of this procedure on the shear strength of the spine has not yet been investigated in vitro. In the present study we determined the ultimate shear force to failure, the displacement and the shear stiffness after performing a laminectomy and a partial facetectomy. Eight lumbar spines of domestic pigs (7 months old) were sectioned to obtain eight L2-L3 and eight L4-L5 motion segments. All segments were loaded with a compression force of 1,600 N. In half of the 16 motion segments a laminectomy and a 50\% partial facetectomy were applied. The median ultimate shear force to failure with laminectomy and partial facetectomy was $1,645 \mathrm{~N}$ (range 1,066$1,985)$ which was significantly smaller $(p=0.012)$ than the ultimate shear force to failure of the control segments (median 2,113, range 1,338-2,659). The median shear stiffness was $197.4 \mathrm{~N} / \mathrm{mm}$ (range 119.2-216.7) with laminectomy and partial facetectomy which was significantly $(p=0.036)$ smaller than the stiffness of the control specimens (median 216.5, 188.1-250.2). It was concluded that
\end{abstract}

G. B. van Solinge · B. J. van Royen

Department of Orthopedic Surgery, VU University Medical

Center, Amsterdam, The Netherlands

A. J. van der Veen

Department of Medical Physics and Technology, VU University

Medical Center, Amsterdam, The Netherlands

J. H. van Dieën · I. Kingma $(\square)$

Faculty of Human Movement Sciences, Research Institute

MOVE, VU University Amsterdam, Van der Boechorststraat 9,

1081 BT Amsterdam, The Netherlands

e-mail: i_kingma@fbw.vu.nl laminectomy and partial facetectomy resulted in $22 \%$ reduction in ultimate shear force to failure and $9 \%$ reduction in shear stiffness. Although relatively small, these effects may explain why patients have an increased risk of sustaining shear force related vertebral fractures after spinal decompression surgery.

Keywords Facetectomy - Laminectomy - Shear strength · Stiffness $\cdot$ Spinal stenosis

\section{Introduction}

Degenerative lumbar spinal stenosis can result in narrowing of the spinal canal. This narrowing can lead to entrapment of the nerve roots and to neurogenic claudication, i.e. pain in the lower extremities while walking or standing. Typical of neurogenic claudication, these symptoms resolve with sitting or lumbar flexion. Degenerative lumbar spinal stenosis [1] is the most common reason for lumbar surgery in patients beyond the age of 65 years [2]. The standard surgical management for degenerative lumbar spinal stenosis is decompression of the spinal canal and the entrapped nerves [3-5]. The pressure can be relieved by a laminectomy, combined with a partial facetectomy. The long-term outcome of this surgery depends on the maintenance of sufficient intervertebral stability. A too large resection may cause instability of the vertebral column [6-11], sometimes resulting in pars interarticularis fractures and spondylolisthesis [12-14]. On the other hand, removing too little bone does not resolve the stenotic or radicular symptoms.

The effect of laminectomy and facetectomy on the stability of the lumbar spine has been studied in vitro $[8,10]$ as well as in finite element studies [6, 15-18]. These 
studies show that after laminectomy and facetectomy the stability is impaired, which would increase the risk of spondylolisthesis. In addition, in vitro experiments have shown that anterior shear loading can lead to bony failure of the posterior elements of the spine, with the pars interarticularis being most frequently affected [19-22]. Similarly it has been shown in in vitro experiments that after removal of the posterior elements compression and bending stiffness are reduced [23, 24] and the strength in shear loading is smaller $[22,25]$. None of these studies measured the shear strength of the vertebral column after laminectomy and a partial facetectomy.

The aim of this study was to investigate the shear strength, in terms of ultimate shear force and displacement to failure and shear stiffness, of the porcine lumbar spine after laminectomy and partial facetectomy, comparable with surgery for spinal stenosis. We hypothesized that laminectomy and partial facetectomy would cause a major decrease of the shear strength.

\section{Methods}

Specimens and specimen preparation

Eight porcine lumbar spines of domestic pigs (mean weight $78 \mathrm{~kg}$, mean age 7 months) were obtained from the slaughterhouse. Specimens were stored frozen at $-20^{\circ} \mathrm{C}$, with the surrounding soft tissue intact. All animals were healthy before they were sacrificed. Prior to testing the segments were thawed and kept wet by $0.9 \%$ saline-soaked gauze. All muscular tissue was removed, but ligaments were left intact. Each lumbar spine was sectioned into two motion segments for testing: L2-L3 and L4-L5. The motion segments were examined for bone abnormalities. For each spine, one of the motion segments was assigned to the control group and one to the treatment group, while counterbalancing L2-L3 and L4-L5 segments over the treatment group and the control group so that both groups consisted of eight L2-L3 and eight L4-L5 segments. In the treatment group, a laminectomy and a partial facetectomy were applied: first, a laminectomy was made with a mechanical $10-\mathrm{mm}$ oscillating saw at level L2 or L4 by removing the spinous process and part of the lamina (Fig. 1). Before performing the partial facetectomy the width of the pars interarticularis was measured with a calliper rule (accuracy one tenth of a millimetre), both at the left and right sides. At half of the width of the pars interarticularis a 2-mm hole was drilled just above the facet joint. The facet joint was left intact. From here, on both sides a partial facetectomy to the midline was performed using a mechanical 4-mm oscillating saw (Fig. 2). Subsequently, the vertebral bodies were embedded in neutral

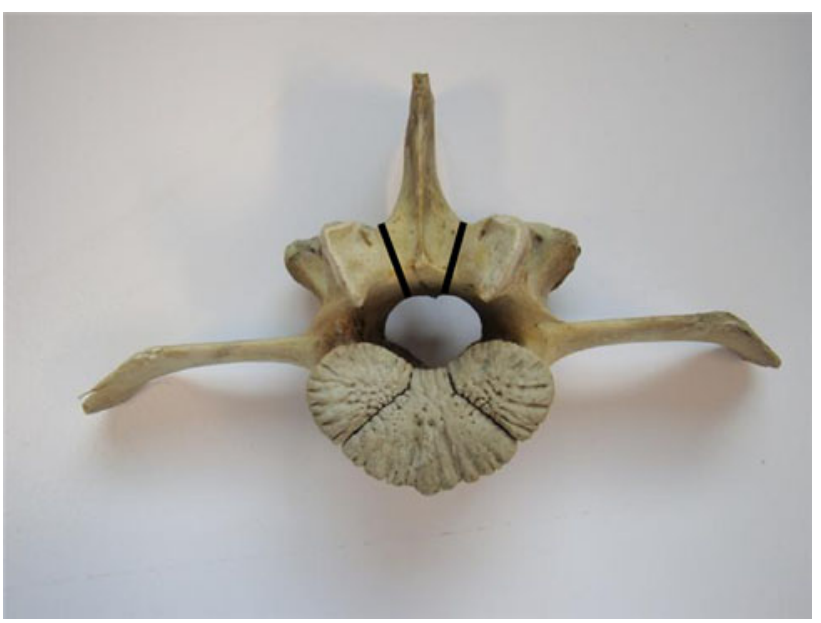

Fig. 1 Vertebra of the porcine lumbar spine. The black lines indicate where the laminectomy was performed

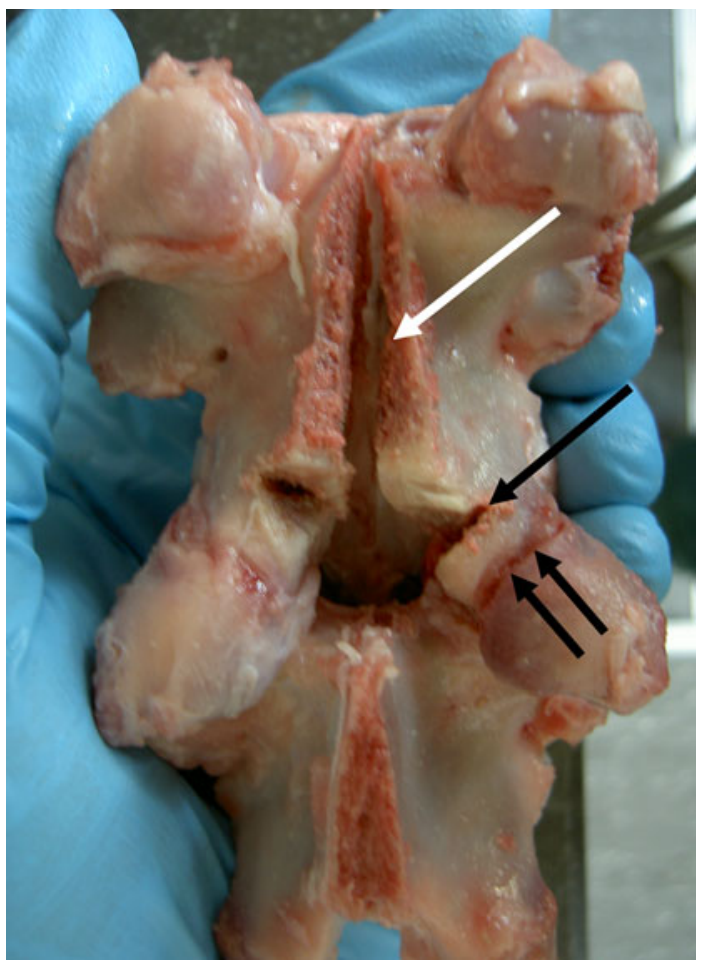

Fig. 2 Dorsal view of a segment before testing. The white arrow shows the laminectomy, the black arrow shows the partial facetectomy. The double black arrows show the facet joint

position in cups with a low melting point $\left(48^{\circ} \mathrm{C}\right)$ bismuth alloy, with the articulating parts remaining outside the bismuth. Prior to embedding screws were drilled into the body of both vertebrae up to a depth of $7 \mathrm{~mm}$ to avoid any movement in the bismuth. For both the treatment and the control groups, the transverse processes were partially removed and for the control group, the dorsal part of the spinous process was removed. Removal of these bony ends 
was applied to promote solid embedding and did not affect the arch or the articulating parts of the vertebra.

\section{Biomechanical testing procedure}

Using a dead weight connected through a pulley system to the plateau, segments were loaded with a compression force of $1,600 \mathrm{~N}$. This load was selected to allow for comparison with previous work [25] and was a compromise between applying compression forces that are sufficiently large to simulate spine loads that occur in vivo when large shear forces are present [26-28], but low enough to avoid damage due to compression forces alone [29]. An anterior shear force was applied on the cranial vertebra using a hydraulic materials testing machine (model 8872; Instron \& IST, Canada). The caudal vertebra was fixed on a plateau that could move in axial and horizontal direction, without allowing any movement in the shear direction (Fig. 3). The only structures resisting shear displacement of the cranial vertebra were the articulations with the caudal vertebra. Shear strength was determined at a displacement rate of $0.1 \mathrm{~mm} / \mathrm{s}$. Force and displacement were recorded and digitized at $100 \mathrm{~Hz}$ (Instron Fast Track 2). The test was stopped after hearing a clear crack or after a large force reduction was seen.

\section{Analysis}

For each of the 16 motion segments tested, the ultimate shear force to failure, i.e. the peak force in the load-

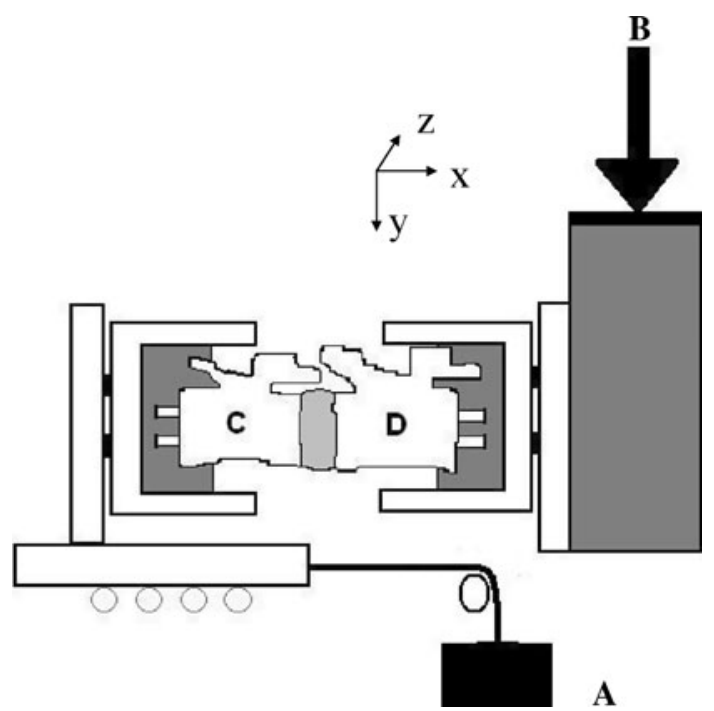

Fig. 3 A schematic picture of the experimental setup. The segments were loaded with $1,600 \mathrm{~N}$ compression force by a dead weight $(A)$ along the $X$-axis, and an anterior shear force $(B)$ along the $Y$-axis. The caudal vertebra $(C)$ could freely move in $X$-direction and axially rotate around the $X$-axis; the cranial vertebra $(D)$ could only move along the $Y$-axis when shear was loaded displacement curve, and the displacement at the instant of ultimate shear force were determined. The average shear stiffness of the segments was calculated from the loaddisplacement curve. The deformation was linear, with an $r^{2}>0.997$ for each individual test, after an initial phase (i.e. after a load of $400 \mathrm{~N}$ ) and up to the first visible sign of failure (i.e. up to over $900 \mathrm{~N}$ in all specimens), and therefore the average stiffness between loads of 400 and $900 \mathrm{~N}$ was calculated. A Wilcoxon signed ranks test was applied to the ultimate shear force at failure, to the displacement at failure and to the shear stiffness between 400 and $900 \mathrm{~N}$. The test was applied both for the factors treatment group (treatment and control) and vertebral level (L2-L3 and L4-L5). Furthermore, the pars width prior to treatment, averaged over the left and right side, was tested for a difference between L2-L3 and L4-L5, again using a Wilcoxon signed ranks test. The statistical analyses were performed using SPSS for Windows version 17.0 (SPSS Inc., Chicago, USA). The significance criterion was set at 0.05. After testing, the mode of failure was established for each specimen by inspection prior to and after dissection.

\section{Results}

No bone abnormalities were found in the tested segments before the shear load was applied. The main site of failure during shear loading (Table 1) was the pars interarticularis for the laminectomy/facetectomy group and the arch for the control group. The median ultimate shear force to failure with laminectomy and partial facetectomy (Table 1) was $1,645 \mathrm{~N}$ (range 1,066-1,985) and this was significantly $(p=0.012)$ smaller than the median ultimate shear force to failure of the control segments $(2,113 \mathrm{~N}$, range 1,338 $2,659)$. The median displacement at the instant of ultimate shear force with laminectomy and partial facetectomy was $9.3 \mathrm{~mm}$ (range 7.5-11.0) and this was not significantly different $(p=0.069)$ from the control segments (median $11.7 \mathrm{~mm}$, range $6.1-13.1)$.

The median shear stiffness between 400 and $900 \mathrm{~N}$ was $197.4 \mathrm{~N} / \mathrm{mm}$ (range 119.2-216.7) with laminectomy and partial facetectomy and this was significantly ( $p=0.036)$ smaller than the median stiffness of the control segments $(216.5 \mathrm{~N} / \mathrm{mm}, 188.1-250.2)$. In percentage the median ultimate shear force to failure with laminectomy and partial facetectomy was $22 \%$ smaller than in the control group. The median shear stiffness between 400 and $900 \mathrm{~N}$ was $9 \%$ smaller than in the control group.

The median width of the pars interarticularis (Table 1) was significantly ( $p=0.018$ ) smaller for the L2-L3 segments $(10.8 \mathrm{~mm}$, range $10.0-11.4)$ than for the L4-L5 segments (12.4 mm, range 11.6-13.3). However, despite this difference in width between the L2-L3 and L4-L5 
Table 1 Ultimate shear force to failure, stiffness, displacement and failure site for each of the specimens tested in the present study

\begin{tabular}{|c|c|c|c|c|c|c|c|c|}
\hline Test & L2-L3 & L4-L5 & $\begin{array}{l}\text { Ultimate shear } \\
\text { force to failure }(\mathrm{N})\end{array}$ & $\begin{array}{l}\text { Place of } \\
\text { occurrence } \\
\text { of fracture }\end{array}$ & $\begin{array}{l}\text { Pars width } \\
\text { right }(\mathrm{mm})\end{array}$ & $\begin{array}{l}\text { Pars width } \\
\text { left }(\mathrm{mm})\end{array}$ & $\begin{array}{l}\text { Average stiffness } \\
\text { between } 400 \text { and } \\
900 \mathrm{~N} \text { load }(\mathrm{N} / \mathrm{mm})\end{array}$ & $\begin{array}{l}\text { Displacement } \\
(\mathrm{mm})\end{array}$ \\
\hline \multicolumn{9}{|c|}{ Treatment group } \\
\hline 1 & - & $\mathrm{X}$ & 1,116 & Pars right + left & 12.3 & 12.5 & 170.8 & 7.5 \\
\hline 2 & $\mathrm{X}$ & - & 1,537 & Pars right & 11.3 & 11.9 & 186.3 & 8.2 \\
\hline 3 & $\mathrm{X}$ & - & 1,066 & Pars right & 10.0 & 10.1 & 119.2 & 9.0 \\
\hline 4 & - & $\mathrm{X}$ & 1,476 & Pars right + left & 12.5 & 11.9 & 171.4 & 9.2 \\
\hline 5 & $\mathrm{X}$ & - & 1,985 & Pars right + left & 11.4 & 11.1 & 208.5 & 11.0 \\
\hline 6 & - & $\mathrm{X}$ & 1,754 & Pars right + end plate & 11.9 & 12.4 & 210.5 & 9.4 \\
\hline 7 & - & $\mathrm{X}$ & 1,794 & Pars right + left & 12.7 & 12.5 & 215.8 & 9.4 \\
\hline 8 & $\mathrm{X}$ & - & 1,753 & Pars left + end plate & 10.8 & 10.8 & 216.7 & 9.5 \\
\hline Media & & & 1,645 & & & & 197.4 & 9.3 \\
\hline Range & & & $1,066-1,985$ & & & & $119.2-216.7$ & $7.5-11.0$ \\
\hline \multicolumn{9}{|c|}{ Control group } \\
\hline 1 & $\mathrm{X}$ & - & 1,712 & Arch right & 10.6 & 10.7 & 231.7 & 8.3 \\
\hline 2 & - & $\mathrm{X}$ & 2,136 & Arch left & 11.7 & 11.5 & 188.1 & 13.1 \\
\hline 3 & - & $\mathrm{X}$ & 1,338 & Arch left & 12.7 & 13.9 & 222.7 & 6.1 \\
\hline 4 & $\mathrm{X}$ & - & 1,995 & Arch left & 9.7 & 10.2 & 200.8 & 11.0 \\
\hline 5 & - & $\mathrm{X}$ & 2,386 & Arch left & 12.0 & 12.7 & 210.2 & 12.6 \\
\hline 6 & $\mathrm{X}$ & - & 2,517 & Pars left + end plate & 10.7 & 10.9 & 250.2 & 12.2 \\
\hline 7 & $\mathrm{X}$ & - & 2,659 & Arch left & 11.4 & 11.3 & 232.8 & 12.6 \\
\hline 8 & - & $\mathrm{X}$ & 2,091 & Arch left & 12.6 & 12.9 & 208.8 & 11.1 \\
\hline Media & & & 2,113 & & & & $188.1-250.2$ & 11.7 \\
\hline Range & & & $1,338-2,659$ & & & & 216.5 & $6.1-13.1$ \\
\hline
\end{tabular}

segments, those segments did not differ in ultimate shear force to failure $(p=0.327)$ or in stiffness $(p=0.575)$. Inspection of load-displacements curves showed, in some cases, sudden small changes in the stiffness of the segments (Fig. 5). These changes always occurred beyond $900 \mathrm{~N}$ loading. We assume that these small changes in stiffness during a test were caused by micro fractures or by a small rotation of one of the segments.

\section{Discussion}

The present study showed that the ultimate shear force to failure of the lumbar porcine spine after laminectomy and partial facetectomy was significantly smaller than the ultimate shear force to failure of the control segments. The shear stiffness of the segments on which the laminectomy and the partial facetectomy were performed, was also significantly smaller. This confirms our hypothesis and is also in line with model studies [15-18] and in vitro studies $[10,24]$ showing reduced stability of the spine after laminectomy and partial facetectomy. Thus, the pars interarticularis contributes substantially to the resistance to shear forces at the lumbar spine and, as such, provides important

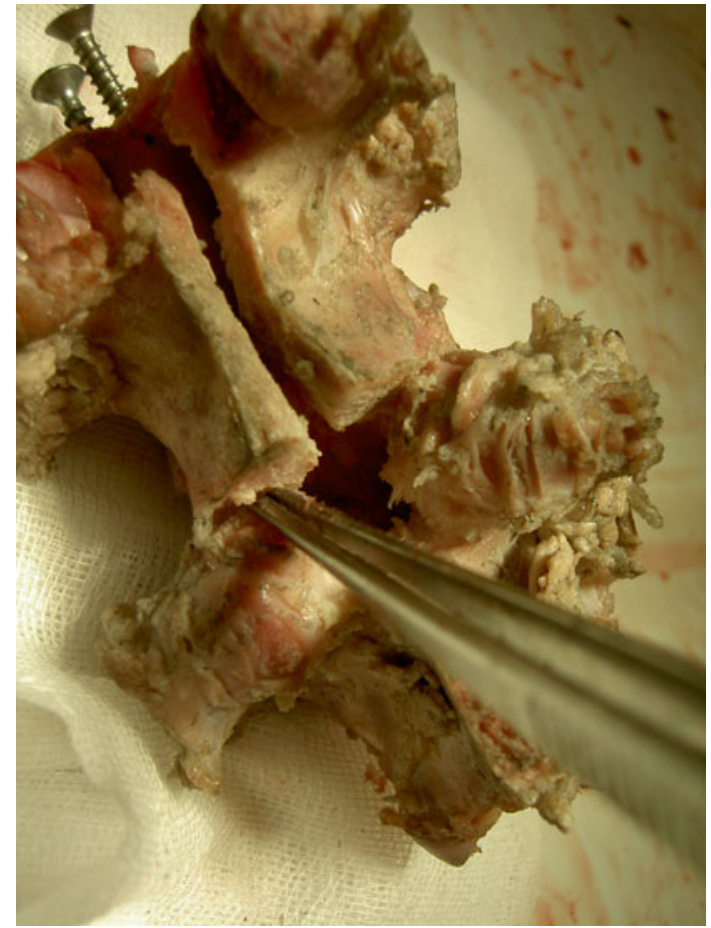

Fig. 4 The tweezers show a pars interarticularis fracture after testing a laminectomy and partial facetectomy segment 


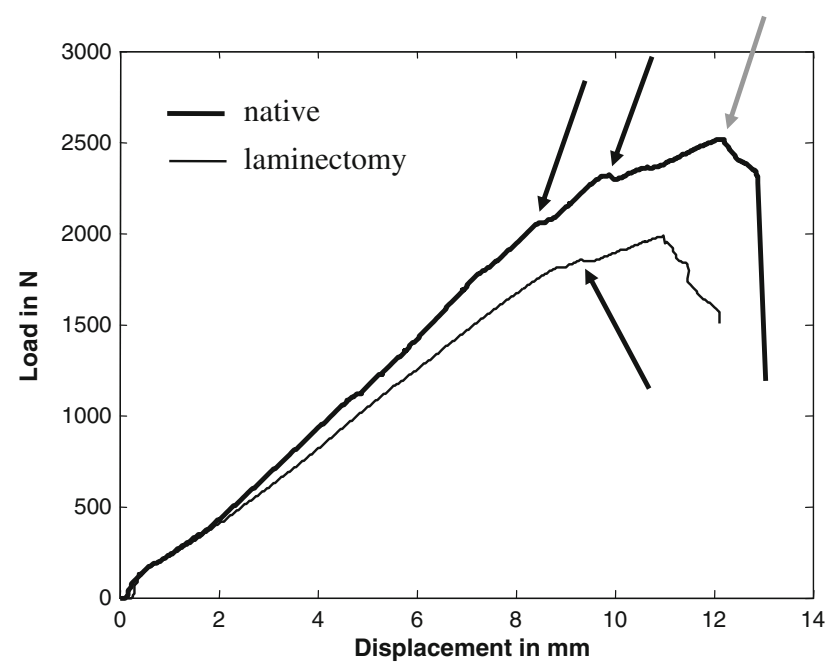

Fig. 5 Load-displacement curves for anterior shear loading. The black arrows show the small changes in stiffness during the test. The grey arrow shows the ultimate shear force to failure

protection against shear injury. Removal of $50 \%$ of the pars interarticularis with a laminectomy resulted, in the present study, in a median reduction of the ultimate shear force to failure of $22 \%$.

Clinically, these results can explain the pars interarticularis fractures and spondylolisthesis that are sometimes seen after decompression of the spinal canal [12-14, 19, 30]. Our results suggest that decompression surgery reduces the injury threshold in shear loading of the lumbar spine. Patients should be informed about their potentially reduced shear injury threshold, with the possibility of causing pars interarticularis fractures and spondylolisthesis. Prevention programmes, aimed at reducing shear loading, may be useful in reducing the incidence of postsurgical shear load induced injury. Our results underline the importance of preserving as much of the pars interarticularis as possible during surgery, but the percentage reduction of ultimate shear force to failure is not proportional with the percentage bone removed. The percentage reduction of ultimate shear force to failure is only about half of the percentage bone that is removed. Partially, this can be explained by the fact that the pars interarticularis is not the only structure resisting shear forces. In fact, the intervertebral disc has been shown to be one of the primary shear-resisting structures when applying forward shear forces $[19,22,25,31]$ and it has been shown to be responsible for $62.5-74 \%$ of the ultimate shear strength $[19,22,31]$.

Another explanation for the finding that removal of 50\% of the bone of the pars interarticularis did not result in a $50 \%$ decrease of ultimate shear force to failure, is that the pars interarticularis is not "the weakest link" prior to surgery. As can be seen in Table 1, the location of failure in the control specimens was seven times the arch of the vertebra and only one time the pars interarticularis.

In the present study, the median ultimate shear force to failure in the control group was 2,113 N, which is comparable with other studies [22, 25, 31]. The shear stiffness reduction in the present study (9\%) was even smaller than the reduction in ultimate shear force to failure $(22 \%)$. Comparably, van Dieen et al. [25] found only $32 \%$ increased amplitude in shear displacement after complete removal of the posterior elements. Those relatively low percentages may be related to the 1,600 $\mathrm{N}$ compression load used in the present study. It has been shown that the shear stiffness of spinal motion segments increases with compressive loading [32, 33]. Indeed, without compressive loading, Lu et al. [23] found a reduction of stiffness of $78 \%$ after removing the complete posterior elements. The difference between the stiffness reduction $(9 \%)$ and the ultimate shear force reduction (22\%) in the present study might be speculated to be due to an increased bony contribution to the stiffness when approaching the ultimate shear load.

It can be noted from Table 1 that fractures were not symmetrically distributed over the left and right sides. All of the specimens were exactly levelled in the middle of the bismuth during testing and the anterior shear load was symmetrically applied on the vertebras in the bismuth. We found no explanation for the occurrence of the asymmetrical arch fractures, and we assume that it is a coincidence.

A limitation of the present study is that we used porcine spines with a mean age of 7 months and not adult human spines. We chose pigs for their specimen homogeneity related to a comparable age, weight, diet, activity level and genetic background between animals [31]. Porcine lumbar segments differ from human lumbar segments. The main difference is the smaller size, while morphological characteristics are similar to human lumbar spines [34]. Multiple studies have shown that mechanical properties like compressive and shear strength in porcine specimens are similar to human lumbar spines [22, 25, 35]. Another limitation of the present study is that we used only a single level of compression force. As indicated earlier, compression is known to increase the shear stiffness of the intervertebral disc, so that the percentages found in the present study would probably be higher when the compression force would have been lower. We selected the present load level because it is a physiologically reasonable level of compression with the applied shear loads and this load was selected to allow for comparison with previous work [25].

It should be noted that surgery for spinal stenosis is mainly applied in patients exceeding the age of 65 years. Most of these patients suffer from osteoporosis [36, 37]. Osteoporosis likely reduces both the stiffness and the ultimate shear strength of the pars interarticularis. 
Furthermore, the intervertebral disc is often degenerated in elderly people. Initially, this results in a loss of (shear) stiffness of the disc, but severely degenerated discs may show enhanced stiffness [19, 30, 31, 34-40]. Therefore, the overall effect of aging on the ultimate shear strength is hard to predict. Clearly, further testing on aged human lumbar spines is warranted.

Another limitation of the present study was that we did not, as common in this kind of surgery, use a Kerrison rongeur to remove the bone. The reason was that pilot work suggested that we could more accurately remove $50 \%$ with a mechanical saw. Nevertheless, the removed bone may not have been exactly $50 \%$. This could have influenced our data. Furthermore, that the strength and stiffness of the removed bone was different from the strength and stiffness of the remaining bone cannot be excluded. Bone density as well as precise quantification of the amount of bone removed might be obtained from 3D CT images, but this was not applied in the present study.

In this study we did not investigate the effects of partial facetectomy and laminectomy on shear strength separately. This choice was made because of the destructive nature of the tests in combination with the goal to simulate the surgical procedure used in patients with spinal stenosis. Finally, we only used a single loading cycle. Cyclic loading might, through visco-elastic behaviour of the intervertebral disc, shift load to the posterior elements [25], thereby enhancing the effect of partial facetectomy and laminectomy on shear strength.

In conclusion, the present study showed that in porcine segments, laminectomy and partial (50\%) facetectomy resulted in $22 \%$ reduction in ultimate shear force to failure and $9 \%$ reduction in shear stiffness. Although relatively small, these effects may explain the high incidence of pars interarticularis fractures and spondylolisthesis in patients after spinal decompression surgery.

Open Access This article is distributed under the terms of the Creative Commons Attribution Noncommercial License which permits any noncommercial use, distribution, and reproduction in any medium, provided the original author(s) and source are credited.

\section{References}

1. Verbiest $H$ (1954) A radicular syndrome from developmental narrowing of the lumbar vertebral canal. J Bone Jt Surg 36B:230 237

2. Weinstein JN, Lurie JD, Tosteson TD, Hanscom B, Tosteson AN, Blood EA et al (2007) Surgical versus nonsurgical treatment for lumbar degenerative spondylolisthesis. New Engl J Med 356:2257-2270

3. Hansraj KK, Cammisa FP Jr, O'Leary PF, Crockett HC, Fras CI, Cohen MS et al (2001) Decompressive surgery for typical lumbar spinal stenosis. Clin Orthop Relat Res 384:10-17
4. Katz JN, Stucki G, Lipson SJ, Fossel AH, Grobler LJ, Weinstein JN (1999) Predictors of surgical outcome in degenerative lumbar spinal stenosis. Spine 24:2229-2233

5. Sanderson PL, Getty CJ (1996) Long-term results of partial undercutting facetectomy for lumbar lateral recess stenosis. Spine 21:1352-1356

6. Guan Y, Yoganandan N, Pintar FA, Maiman DJ (2007) Effects of total facetectomy on the stability of lumbosacral spine. Biomed Sci Instrum 43:81-85

7. Johnsson KE, Willner S, Johnsson K (1986) Postoperative instability after decompression for lumbar spinal stenosis. Spine 2:107-110

8. Kato Y, Panjabi MM, Nibu K (1998) Biomechanical study of lumbar spinal stability after osteoplastic laminectomy. J Spinal Disord 11:146-150

9. Lee CK (1983) Lumbar spinal instability (olisthesis) after extensive posterior spinal decompression. Spine 8:429-433

10. Tai CL, Hsieh PH, Chen WP, Chen LH, Chen WJ, Lai PL (2008) Biomechanical comparison of lumbar spine instability between laminectomy and bilateral laminotomy for spinal stenosis syndrome-an experimental study in porcine model. BMC Musculoskelet Disord 9:84

11. Weiner BK, Fraser RD, Peterson M (1999) Spinous process osteotomies to facilitate lumbar decompressive surgery. Spine 24:62-66

12. Beadon K, Johnston JD, Siggers K, Itshayek E, Cripton PA (2008) A repeatable ex vivo model of spondylolysis and spondylolisthesis. Spine 33:2387-2393

13. Efstathiou P, Moskovich R, Casar R, Magnisalis E (1996) A biomechanical evaluation of internal lumbar laminoplasty: the preservation of spinal stability during laminectomy for degenerative spinal stenosis. Bull Hosp Jt Dis 55:7-11

14. Rothman SL, Glenn WV Jr, Kerber CW (1985) Postoperative fractures of lumbar articular facets: occult cause of radiculopathy. Am J Roentgenol 145:779-784

15. Lee KK, Teo EC (2004) Effects of laminectomy and facetectomy on the stability of the lumbar motion segment. Med Eng Phys 26:183-192

16. Lee KK, Teo EC, Qiu TX, Yang K (2004) Effect of facetectomy on lumbar spinal stability under sagittal plane loadings. Spine 29:1624-1631

17. Teo EC, Lee KK, Qiu TX, Ng HW, Yang K (2004) The biomechanics of lumbar graded facetectomy under anterior-shear load. IEEE Trans Biomed Eng 51:443-449

18. Zander T, Rohlmann A, Klockner C, Bergmann G (2003) Influence of graded facetectomy and laminectomy on spinal biomechanics. Eur Spine J 12:427-434

19. Cripton PA, Berleman U, Visarius H (1995) Response of the lumbar spine due to shear loading. Symposium: Injury prevention through biomechanics. Detroit Wayne State University, pp 111-126

20. Cyron BM, Hutton WC, Troup JD (1976) Spondylolytic fractures. J Bone Jt Surg 58B:462-466

21. Newman PH (1963) The etiology of spondylolisthesis. J Bone Jt Surg 45:39-59

22. Yingling VR, McGill SM (1999) Anterior shear of spinal motion segments. Kinematics, kinetics, and resultant injuries observed in a porcine model. Spine 24:1882-1889

23. Lu WW, Luk KD, Holmes AD, Cheung KM, Leong JC (2005) Pure shear properties of lumbar spinal joints and the effect of tissue sectioning on load sharing. Spine 30:E204-E209

24. Okawa A, Shinomiya K, Takakuda K, Nakai O (1996) A cadaveric study on the stability of lumbar segment after partial laminotomy and facetectomy with intact posterior ligaments. J Spinal Disord 9:518-526 
25. van Dieen JH, van der Veen A, van Royen BJ, Kingma I (2006) Fatigue failure in shear loading of porcine lumbar spine segments. Spine 31:E494-E498

26. Kingma I, Faber GS, Bakker AJ, van Dieen JH (2006) Can low back loading during lifting be reduced by placing one leg beside the object to be lifted? Phys Ther 86:1091-1105

27. Kingma I, Staudenmann D, van Dieen JH (2007) Trunk muscle activation and associated lumbar spine joint shear forces under different levels of external forward force applied to the trunk. J Electromyogr Kinesiol 17:14-24

28. van Dieen JH, Kingma I (2005) Effects of antagonistic co-contraction on differences between electromyography based and optimization based estimates of spinal forces. Ergonomics 48:411-426

29. Brinckmann P, Biggemann M, Hilweg D (1989) Prediction of the compressive strength of human lumbar vertebrae. Spine 14:606-610

30. Guigui P, Dessarts I, Morvan G, Benoist M, Lassale B, Deburge A (1998) Fractures of the ischium after laminoarthrectomy. Retrospective study of a series of 31 patients. Rev Chir Orthop Reparatrice Appar Mot 84:247-257

31. Yingling VR, McGill SM (1999) Mechanical properties and failure mechanics of the spine under posterior shear load: observations from a porcine model. J Spinal Disord 12:501-508

32. Gardner-Morse MG, Stokes IA, Churchill D, Badger G (2002) Motion segment stiffness measured without physiological levels of axial compressive preload underestimates the in vivo values in all six degrees of freedom. Stud Health Technol Inform 91:167172
33. Stokes IA, Gardner-Morse M, Churchill D, Laible JP (2002) Measurement of a spinal motion segment stiffness matrix. J Biomech 35:517-521

34. McLain RF, Yerby SA, Moseley TA (2002) Comparative morphometry of L4 vertebrae: comparison of large animal models for the human lumbar spine. Spine 27:E200-E206

35. Tsai KH, Chang GL, Lin RM (1997) Differences in mechanical response between fractured and non-fractured spines under highspeed impact. Clin Biomech 12:445-451

36. Cummings SR, Kelsey JL, Nevitt MC, O’Dowd KJ (1985) Epidemiology of osteoporosis and osteoporotic fractures. Epidemiol Rev 7:178-208

37. Yoshimura N, Muraki S, Oka H, Mabuchi A, Kinoshita $\mathrm{H}$, Yosihda M et al (2009) Epidemiology of lumbar osteoporosis and osteoarthritis and their causal relationship-is osteoarthritis a predictor for osteoporosis or vice versa? The Miyama study. Osteoporos Int 20:999-1008

38. Boos N, Weissbach S, Rohrbach H, Weiler C, Spratt KF, Nerlich AG (2002) Classification of age-related changes in lumbar intervertebral discs: 2002 Volvo Award in basic science. Spine 27:2631-2644

39. Fujiwara A, Tamai K, An HS, Kurihashi T, Lim TH, Yoshida H et al (2000) The relationship between disc degeneration, facet joint osteoarthritis, and stability of the degenerative lumbar spine. J Spinal Disord 13:444-450

40. Schmidt TA, An HS, Lim TH, Nowicki BH, Haughton VM (1998) The stiffness of lumbar spinal motion segments with a high-intensity zone in the anulus fibrosus. Spine 23:2167-2173 